Conway, M. A., Loveday, C. and Cole, Scott ORCID: https://orcid.org/0000-0001-8176-283X (2016) The remembering-imagining system. Memory Studies, 9 (3). pp. 256265.

Downloaded from: http://ray.yorksj.ac.uk/id/eprint/2144/

The version presented here may differ from the published version or version of record. If you intend to cite from the work you are advised to consult the publisher's version: https://doi.org/10.1177/1750698016645231

Research at York St John (RaY) is an institutional repository. It supports the principles of open access by making the research outputs of the University available in digital form. Copyright of the items stored in RaY reside with the authors and/or other copyright owners. Users may access full text items free of charge, and may download a copy for private study or non-commercial research. For further reuse terms, see licence terms governing individual outputs. Institutional Repository Policy Statement

\title{
RaY
}

Research at the University of York St John

For more information please contact RaY at ray@yorksj.ac.uk 
RUNNING HEAD: Remembering \& Imagining

The Remembering-Imagining System

\author{
Martin A. Conway \\ Centre for Memory \& Law \\ Department of Psychology \\ City University London, U.K. \\ Catherine Loveday \\ Department of Psychology \\ University of Westminster, U.K. \\ \& \\ Scott N. Cole \\ Department of Psychology \\ University of York St. John, U.K.
}

This is an Accepted Manuscript of an article published by Sage in Memory Studies, available online soon: http://www.mss.sagepub.com

Correspondence to:

Professor Martin A. Conway, FRSA, FBPsS, FPS, FASS

Centre for Memory \& Law, Director

Department of Psychology, Head

City University,

Northampton Square,

London, EC1V OHB

Email: Martin.Conway.1@city.ac.uk 
Sunday, August 16, 2015

\begin{abstract}
$\underline{\text { Abstract }}$
Remembering and imagining are intricately related, particularly in imagining the future: episodic future thinking. It is proposed that remembering the recent past and imagining the near future take place in what we term the remembering-imagining system (RIS). The RIS renders recently formed episodic memories and episodic imagined near future events highly accessible. We suggest that this serves the purpose of integrating past, current, and future goal-related activities. When the RIS is compromised, following brain damage and in psychological illnesses, the future cannot be effectively imagined and episodic future thinking may become dominated by dysfunctional images of the future.
\end{abstract}

Keywords. Episodic simulation, episodic future thinking, amnesia, psychological illness, retention interval, consciousness, autobiographical memory, episodic memory. Imagining. 
A recent and welcome development in memory research is an emerging interest in the future, particularly what has been termed episodic future thinking, or episodic simulation i.e. imagining future events (both plausible and implausible). It is clear, however, that imagining the future owes much to the ability to remember the past (Cole, Morrision, \& Conway, 2013; Hassabis \& Maguire, 2007; Merck, Topcu, \& Hirst, submitted for publication; Schacter \& Addis, 2007, 2008; Schacter \& Madore, submitted for publication; Suddendorf \& Corballis, 2007; Tulving, 2002) as does generating intentionally false memories (Dudai \& Edelson, submitted for publication; Justice, Morrison, \& Conway, 2013; Stroumsa, submitted for publication). Moreover, in terms of understanding the brain basis of remembering and imagining it seems that both memories and episodic simulations of the future are mediated in large part by the same neural networks. In a recent review of the neuroimaging research, Schacter, Chamberlin, Gaesser, and Gerlach (2012, p.250) quoted Bernstein and Loftus (2009), who concluded, based on their own review of cognitive and neuroimagining studies of true versus false memories, that "it might be virtually impossible to tell reliably if a particular memory is true or false without independent corroboration (p.373)”. On the basis of this evidence it was suggested (Conway, 2009) that perhaps we should be using the term remembering-imagining system (RIS) rather than simply memory system. The RIS is considered further below but first I will consider some aspects of the future.

\section{The Problem Of the Future}

In classical physics/mechanics a system, a collection of objects e.g. particles, fields, waves, etc. is deterministic and reversible (Susskind \& Hrabovshy, 2013). This 
means that given the laws that govern the system and its changes are known, a future state can be predicted exactly. Similarly knowing the state of a system at any given time means that the state of the system at an earlier or later time can be precisely established. Supposing we knew the laws that governed the cognitive, mind/brain, system, could we then, for any given individual, predict the exact state of the system at a future point? I suggest that we could not, (see Dudai \& Edelson, submitted for publication, for related arguments). Just as in certain areas of physics, e.g. quantum mechanics, it is not possible to precisely predict a future state of a system, so with people the future is only probable. However, once a future state has come into being it may be possible, to at least some extent, to work back to previous states. Thus, the cognitive system may be retrospectively reversible (a point interestingly made by Freud, 1920, in the case of psychological states, which given the initial conditions cannot be predicted but working back to initial conditions is at least partly possible). Nevertheless, retrospectively reversible or not, given that there are an infinite number of indeterminate possible futures, this poses a major adaptive problem for goal-driven organisms. This is particularly so as the end point of all unrealized goals lies somewhere in the future. Indeed, in order to have a goal a future state has to be anticipated and often consciously imagined (Cole \& Berntsen, 2015).

For many species the future is adapted to possibly by a general preparedness to meet environmental contingencies. This is perhaps one of the simplest ways to deal with the problem of the future. (Amusingly reflected, perhaps, in the motto of the Boy and Girl Scouts, 'Be prepared!', Baden-Powell, 1908). No doubt all species have this general preparedness, however in our own species more complicated forms of cognition have arisen to anticipate possible futures and also, importantly, to constrain 
what the future can possibly be. Society and culture generally may be one way of dealing with a potentially limitless set of futures, and that is because they constrain possibilities (Merck, et al., submitted for publication; Wang, submitted for publication). Just as memory, especially autobiographical memory constrains the self - it limits the universe of possible future selves (Conway, 2005). Thus, memory, society, and culture constrain the range of possible futures by providing the context in which the future will most probably occur (Welker, submitted for publication). In the case of individuals we have argued that there is what we conceive of as an extended form of consciousness that consists of memories of the recent past and images and expectations of the near future and it is this form of extended consciousness that we have termed the remembering-imagining system.

\section{The Remembering-Imagining System (RIS)}

We visualize the RIS as a bell curve (of consciousness) moving through time with the peak of the curve as 'now' or the present moment, cf. Stern (2004). To the left of the peak is a declining curve that represents decreasing memory access for the recent past as the retention interval increases, and to the right of 'now' another decreasing curve that represents the specificity of imagined future events, see Figure 1. The RIS then posits that we have an awareness of the recent past and near future that declines into lowered memory accessibility as the retention interval from 'now' increases. Conversely, future imagined events - episodic simulations - decrease in episodic specificity declining into the schematic/generic/stereotypical, culturally specified (Berntsen \& Bohn, 2010; Stroumsa, submitted for publication) future memories, as the distance between 'now' and the future increases. The boundaries of 
the RIF are then constantly changing and this is reflected in our constantly changing awareness of the near past and the near future.

Figure 1 about here

To what extent does the idealized representation of the RIS shown in Figure 1 accurately reflect our memory for the recent past and imaginations of the near future? In a recent study we (Loveday \& Conway, 2015) had people list all the personal events they could remember for each of the past 5 days and all the personal events that they the imagined could plausibly occur on each of the next 5 days. The numbers of remembered and imagined future events for each are shown in Figure 2. Note that, we specifically avoided recall from weekends as we suspected these might feature more distinctive events and so somewhat artificially inflate the endpoints of the 5-day periods we were sampling. Nonetheless, in pilot work recently conducted we have found a similar curve, somewhat more pronounced, for events remembered and imagined one month into the past one month into the future.

Figure 2 about here

It can be seen in Figure 2 that the number of recent memories that can be accessed decreases rapidly over the first 3 days but then seems to stabilize and even increase slightly at a retention interval of 5 days. Also, interestingly, the number of memories recalled on the first day averaged at about 9 memories and varied between 6 to 12 events over participants but most recalled 7 to 9 events. The specific instruction to participants was to 'recall as many events as you can from yesterday 
and then from the day before, going back 5 days'. What an 'event' was, was left to each participant to decide. The events listed typically were of discrete series of actions with beginnings and endings marked by changes in actions, locations, and goals. For example, “meeting a friend, X, for lunch” and then "attending a lecture on Y”, with each event description containing contextual episodic details. The number of contextualizing episodic details (essentially who, what, where, and when, plus some other more idiosyncratic details) listed for each memory decreased over the 5-day retention interval. Thus, the memories not only became fewer they also became less specific as the retention interval increased (see too Stroumsa, submitted for publication).

For imagined future events the decline was from a mean of 5 events for tomorrow to a mean of 4.3 events in 5 days time, a reliable but less steep decline. However, the specificity of the imagined future events also decreased as the time interval increased. For example, a typical imagined event for tomorrow might be "going to the gym at 5 with X \& Y tomorrow evening for our zumba class" whereas a typical imagined event in 5 days might be more "going to the pub”, "going to the cinema”, etc. Thus, the further away in time the imagined events the more typical and routine they became with less imagined episodic detail. In other recent research (Loveday \& Conway, 2015) that collected imagined future events from 1 to 5 and 5 to 10 years hence, outside the range of the RIS, the imagined events were more typical of events from 'life scripts' (Berntsen \& Rubin, 2004) and were low in episodic content. It seems then that the episodic content of imagined future fades into culturally determined events, such as getting married, having children, pursuing a career, retirement, etc. as episodic future thinking turns into culturally expected future 
events. We see this phenomenon of fading episodic detail in memories of the past and imagining future events more as a bias in the RIS rather than a sort of episodic boundary. There are always some events from the past that can be recalled with extensive episodic detail and, similarly, some events from the future that can be imagined with rich episodic detail. We believe not that not that this cannot be done, but rather that it typically is not done.

Another feature of the RIS is that it is present during periods of unconsciousness, e.g. during periods of sleep. Indeed it may be during sleep that recent and future memories become in some way connected, perhaps by integration/consolidation with common and current goals (see Diekelmann \& Born, 2010). In order to explore this we had individuals record their waking thoughts immediately upon awakening with the expectations that many of these would be about up-coming events and the recent past. Note that recording took place during the period of the awakening cortisol response (ACR), when activation rises in the medial temporal lobe memory system and, of course, frontal systems that have been to some extent dysfacilitated during sleep regain their normal levels of activation. This may reflect the RIS coming back on line too. Thoughts were also sampled mid-way through the day and again in the evening. Classification of awakening thoughts is shown in Figure 3.

Figure 3 about here

The two major categories of awakening thoughts are orientation thoughts e.g. 'What time is it?' and thoughts about the ‘close/near' future, e.g. 'what am I doing 
today?’ There were relatively few thoughts about the recent past. These findings suggest, perhaps, that the RIS is re-engaging with future episodic imaginings after a period of disengagement during sleep. Possibly the ACR in part facilitates a reengagement of the medial temporal lobe memory system with executive control systems in frontal regions and, thereby, reconnects to representations of the immediate future. Thoughts at later points in the day were also goal-oriented but to near activities and very recent memories often of task completion, see Figure 3 and Loveday and Conway (2015).

There is some evidence then for the idealized bell-shaped curve of the RIS shown in Figure 1 and the future component of the RIS seems highly active upon awakening. However, although changes in the accessibility of memories of recent past events and episodic memories of near future events are reflected in decreasing numbers of events recalled with increasing retention interval there are, as noted above, other more qualitative changes in the episodicity of what is recalled. Thus, the episodicity of both memories of past and future events decreases with increasing retention interval (Stroumsa, submitted for publication; Welker, submitted for publication). An interesting question that then arises is: What is the range of the RIS? Where do its boundaries lie? We suggest that the RIS is part of the goal system, cf. Conway \& Pleydell-Pearce (2000) and maintains access to memories of recent events that themselves support plausible imaginings of near future events. Raised access to recent memories keeps us informed of specific progress with current goals and with specific goal-related activities that are up-coming in the near future. The range of episodic memories with RIS-raised accessibility may be determined by how the content of those memories continues to inform goal activities, perhaps by accurately 
predicting future events. To take a mundane example, for a student an episodic memory of having completed a coursework assignment, say last night, might lead to an episodic simulation of handing in the completed course work in the department the following day. This simulation when enacted will, in turn, become a recent episodic memory that maintains a highly accessible record of achievement of a specific goal (embedded in a much more complex goal hierarchy of getting a (good) degree). It is important to note that it is not the simulation that becomes a memory but rather its enactment that leads to a new episodic memory or set of episodic memories (Conway, 2009). Thus the episodic simulation through enactment ${ }^{1}$ has now become a new episodic memory that may remain highly accessible in the RIS with accessibility gradually decreasing with time, perhaps over only a few days in this example. One implication of this view of the RIS is that episodic memory is critically important to episodic future thinking, because without it a person could not generate effective episodic simulations based on recent episodic memories of goal-related actions.

\section{Dysfunctional RIS}

Related to the notion that recent episodic memories allow the formation of (effective or adaptive) episodic simulations (see Schacter, Addis, Hassabis, et al., 2012 for a detailed review; Schacter \& Madore, submitted for publication) we recently had the opportunity to study future simulations in a densely amnesic patient (Cole, Morrison, Barak, Pauly-Takacs, \& Conway, 2015). Patient HCM, a 66 year-old highly educated married man with four adult children suffered a series of

\footnotetext{
${ }^{1}$ Although beyond the scope of the present work an especially interesting question is how episodic simulations and their later enactments can be distinguished in memory.
} 
cardiovascular incidents leading to hospitalization in a rehabilitation centre with 24hour care. Although separated from his wife his children visited regularly. Earliest evidence of brain damage was a cardiovascular accident in 1998 (at 51 years old). This resulted in a left lateralised haemorrhage which required a craniotomy to alleviate pressure. He also sustained two traumatic head injuries, one in 2000 (at 53 years) when he was assaulted with a blow to the head and one in 2002 (at 55) when he fell down a staircase. After being hospitalised, he was admitted to a specialist neurobehavioural unit for assessment of people with acquired brain injury and aiming to remediate ongoing cognitive, behavioural, and physical deficits. In summary the conclusion of the assessment was that HCM had multiple diffusely spread infarcts indicative of global atrophy extending to both cortical and subcortical regions.

HCM undertook a wide-ranging neuropsychological test battery examining his cognitive abilities in a number of domains including executive processing, memory, and episodic future thinking. Although HCM was enthusiastic about taking the test battery he required 11 testing sessions to complete the tests. This was due to HCM repeatedly stopping testing when he became aware of his inability to complete tasks to pre-injury levels. This suggests that although he had online awareness of his reduced abilities, this did not augment his global self-knowledge of his current abilities (see Toglia \& Kirk, 2000). HCM’s language was spared but his working memory was impaired. His orientation showed that HCM had difficulty in estimating current temporal information and was unable to provide an answer concerning the current day, date or month. Also, he was unable to recall when he was admitted to the rehabilitation unit. His current year estimate predated the current year by a decade. Knowledge of current location was more accurate: HCM accurately described the 
country, city, and building ('hospital building') indicating that he did not have global unawareness of his current situation. Finally, he was generally unable to remember people he had recently encountered. This anterograde amnesia (AA) was strikingly evident in tests of memory: in immediate recall he could recall, to some extent, parts of stories and words he had studied, however, following even short delays prior to recall he recalled nothing and was at floor on all tests.

HCM’s profile was that of patient with some spared intellectual capacity, reasonably good language skills, an impaired working memory, but spared short-term memory, and a severely dense AA. He had in effect lost the ability to form new episodic memories. Examination of his autobiographical memory found some recall of events from early in his life, a few from the period prior to his first stroke, and good retention of factual knowledge of his life up to early adulthood. There were, however, few specific memories from later life and none at all from the past five years. He could not recall the name of a single one of his carers. He had then, in addition to his AA a temporally-graded retrograde amnesia (RA). Consequently, HCM had a severely damaged RIS and it seemed that his ability for episodic simulation of the future may have been compromised. It was decided, therefore, to investigate his ability for future episodic simulation. In order to do this we created a short and simple Mental Time Travel Questionnaire that required HCM and non-brain damaged matched controls to either recall specific autobiographical memories to a series of temporal cues e.g. recall an event from last weekend or think of specific future events e.g. think of an event that might happen next weekend. Plausibility of responses were verified in HCM's case with one of his sons and for the controls with family members. 
HCM recalled some past events and only a few future events. His future episodic simulations were, however, highly implausible. For example, he stated that he would invite his family to his apartment for a family gathering. In fact, he owned a local apartment but was no longer able to access this due to mobility problems. Clinical staff confirmed he had not resided at his apartment since admission and was not expected to live there in the future. Nevertheless, HCM voluntarily imagined a future scenario involving his apartment. In a similar vein, in 5-10 years he envisioned 'passing' a variety of clinical examinations and moving back into his apartment. Both of these events would be unlikely to occur, according to clinicians and his son, suggesting that his future thoughts were out-dated and related not to memories of his current situation but rather to memories of the conditions that existed in his life before his first brain injury years previously. It is important to note that HCM did not confabulate those memories he was able to access and it was only in imagining future events that his memories became implausible. In general, HCM's descriptions of his personal past and future was marked by a sparcity of episodic information, similar to the blankness of the past and future reported by patient KC (Tulving, 1985). We note here too the similarity of HCM to those agnosognosic Alzheimer's patients described as having a "petrified self” (Morgrabi, Brown, \& Morris, 2009). Plausibility is perhaps one of the major differences between images of a future that are effective and adaptive in implementing goals and those that are not. Having an intact and functioning RIS facilitates the connection of memories of the recent past to episodic simulation of the near future. 
HCM is a patient not only stranded in the past but also in the future, without a record of the recent past he cannot imagine future events that are plausible and linked to his current situation - linked to 'now' (see Cole, Fotopoulou, Oddy, \& Moulin, 2014, for further discussion of memory plausibility, Stroumsa, submitted for publication, for an interesting and related cultural discussion, and Young, submitted for publication, for a related discussion of 'absence'). We have noted previously the constraining effect of memories generally on the self, e.g. Conway, (2005), and how in some psychological illnesses, in schizophrenic delusions for example, this constraining relation appears to break down. This raises the interesting possibility of having episodic future simulation that are not adaptive or effective but instead are maladaptive and dysfunctional. Consider, for example, a patient with social phobia who believed that if she went out of her house she would end up in a supermarket and somehow be dragged into one of the large freezers containing bags of frozen vegetables and pulled under and ‘drown’ (Day, Holmes, \& Hackman, 2004). She had a powerful and intrusive episodic future simulation of this happening and this image of the future event prevented her from leaving the house. Such images of future events are not uncommon in a range of psychological illnesses (Macleaod, submitted for publication). For instance suicide attempters often report what Holmes, Crane, Fennell, \& Williams (2007, Table 2) have termed ‘flash-forwards’ (see too Crane, Shah, Barnhofer, \& Holmes, 2012, also Table 2). The flash-forwards in these patients are to episodic simulations of their own deaths in which they 'see' their dead body, e.g. at the foot of the cliff, under the wheels of a train, etc. Such intrusive future episodic images may be associated with further attempts at suicide. Episodic simulations of the future in psychological illnesses may support and even motivate dysfunctional behaviour and beliefs (MacLeod, submitted for publication). 


\section{Concluding Comment}

The RIS is a hypothesis about the raised accessibility and increased specificity of episodic simulations of the recent past and near future. Importantly, the RIS only exists now, cf. Stern, 2004, for an exegesis of the concept 'now'. It is an expansion of 'now' to encompass records of recent and associated upcoming goal-related activities (see Johnson \& Sherman, 1990, for a particularly interesting discussion of the integration of past, present, and future). Its boundaries are constantly changing as goals are completed, abandoned, and/or replaced over time. If the ability to form episodic memories is lost, as in AA, then the RIS breaks down and effective future simulations are no longer possible. It is notable too, that when this occurs the ability to operate adaptively and effectively in one's life is also severely compromised. HCM for instance, and as is the case with many AA patients, required 24-hour care.

The idea that episodic future simulations should be effective and adaptive is important. After all, any future could be imagined but only a limited number are plausible and probable. We suggest that the degree to which future episodic simulations are adaptive/effective is determined by the strength of their association to specific episodic memories of the recent past (Merck, et al., submitted for publication; Schacter \& Medore, submitted for publication). The degree to which they are not associated with recent episodic memories reflects a malfunctioning RIS, possibly due to brain damage or to the effects of a psychological illness. Nevertheless, for many individuals there may be some highly specific future episodic simulations that are implausible because they have a low probability of occurrence e.g. winning the 
lottery, etc, and these may be linked to recent episodic memories, e.g. buying a ticket, indicating normally functioning RIS. Possibly, the number of plausible to implausible episodic simulations held by an individual is some sort of index of mental health or well-being more generally (MacLeod, submitted for publication). 


\section{$\underline{\text { References }}$}

Baden-Powell, R (1908). Scouting for Boys (1st bookform, cloth-bound ed.). C. Arthur Pearson Ltd: London.

Bernstein, DM \& Loftus, EF (2009). How to tell if a particular memory is true or false. Perspectives on Psychological Science, 4, 370-374.

Berntsen, D \& Bohn, A (2010). Remembering and forecasting: The relation between autobiographical memory and episodic future thinking. Memory \& Cognition, 38, 265-278.

Berntsen, D \& Rubin, DC (2004). Cultural life scripts structure recall from autobiographical memory. Memory \& Cognition, 32, 427-442.

Cole, SN \& Berntsen, D, (2015). Do future thoughts reflect personal goals? Current concerns and mental time travel into the past and future. Quarterly Journal of Experimental Psychology, in press.

Cole, SN, Fotopoulou, A, Oddy, M, \& Moulin, CJA, (2014). Implausible future events in a confabulating patient with an anterior communicating artery aneurism. Neurocase, 20, 208-224. doi: 10.1080/13554794.2012.741259 
Cole, SN, Morrison, CM \& Conway, MA, (2013). Episodic future thinking: Linking neuropsychological performance and episodic detail in young and old adults. Quarterly Journal of Experimental Psychology, 66, 1687-1706. doi: 10.1080/17470218.2012.758157.

Cole, SN, Morrison, CM, Barak, O, Pauly-Takas, K, \& Conway, MA, (2015). Amnesia and future thinking: Exploring the role of memory in the quantity and quality of future thoughts. British Journal of Neuropsychology, in press.

Conway, MA, (2005). Memory and the self. Journal of Memory and Language, 53(4), 594-628.

Conway, MA, (2009). Episodic memories. Neuropsychologia, 47, 2305-2313.

Conway, MA, \& Pleydell-Pearce, CW, (2000) The construction of autobiographical memories in the self memory system. Psychological Review,107, 261-288.

Crane, C, Shah, D, Barnhofer, T, \& Holmes, EA, (2012). Suicidal imagery in a previously depressed community sample. Clinical Psychology and Psychiatry, 19, 5769.

Day, S, Holmes, EA, \& Hackman, A, (2004). Occurrence of imagery and its link with early memories in agrophobia. Memory, 12(4), 416-427. doi:10.1080/09658210444000034 
Diekelmann, S., \& Born, J. (2010). The memory function of sleep. Nature Rev Neurosci. 11(2):114-26.

Dudai, Y, \& Edelson, M, Personal memory: Is it personal? Is it memory? submitted for publication.

Fivush, R, Merrill, N, An ecological systems approach to family narratives. submitted for publication

Freud, S, (1920). The psychogenesis of a case of homosexuality in a woman. Standard Edition (Vol. 18, pp. 145-172). London: Hogarth Press, 1955.

Hassabis, D, \& Maguire, EA, (2007). Deconstructing episodic memory with construction. Trends in Cognitive Sciences, 11, 299-306.

doi:10.1016/j.tics.2007.05.001

Holmes, EA, Crane, C, Fennell, MJV, \& Williams, J.M.G (2007). Imagery about suicide in depression - "Flash-forwards"? Jounral of Behaviour Therapy and Experimental Psychiatry, 38, 423-434.

Johnson, MK \& Sherman, SJ, (1990). Constructing and reconstructing the past and the future in the present. In ET Higgins \& RM Sorrentino (Eds.), Handbook of Motivation and Cognition: Foundations of Social Behaviour (Vol 2, pp. 482-526). New York: The Guildford Press. 
Justice, LV, Morrison, CM, \& Conway, MA, (2013). True and fabricated memories. Quarterly Journal Of Experimental Psychology, 66, 1196-1203. doi: 10.1080/17470218.2012.734832

Loveday, C, \& Conway, MA, (2015). Recalling recent episodic memories and near future events. In preparation.

MacLeod, AK, Prospection, well-being and memory. submitted for publication.

Merck, C, Topcu, MN, Hirst, W, Collective mental time travel: Creating a shared future through our shared past. Submitted for publication.

Morgrabi, D.C., Brown, R.G., \& Morris, R.G. (2009). Anosognosia in Alzheimer's disease - The petrified self. Consciousness and Cognition, 18, 989-1003.

Rubin, DC, \& Berntsen, D, (2003). Life scripts help to maintain of highly positive, but not highly negative events. Memory \& Cognition, 31, 1-14.

Schacter, DL, \& Addis, DR, (2007). The cognitive neuroscience of constructive memory: Remembering the past and imagining the future. Philosophical Transactions of the Royal Society of London (B), 362, 773-786. doi:10.1098/rstb.2007.2087

Schacter, DL, Addis, DR, Hassabis, D, Martin, VC, Spreng, RN, \& Szpunar, KK, (2012). The future of memory: Remembering, imagining, and the brain. Neuron, 76, 677-694. doi:10.1016/j.neuron.2012.11.001 
Schacter, DL, Chamberlain, J, Gaesser, B, \& Gerlach, KD, (2012).

Neuroimagining of true, false, and imaginary memories. In L.Nadel \& W.P. SinnottArmstrong, Memory and Law. (pp. 233-262). New York: Oxford University Press.

Schacter, DL, \& Madore, KP, Remembering the past and imagining the future: Identifying and enhancing the contribution of episodic memory. Submitted for publication.

Stern, DN, (2004). The Present Moment in Psychotherapy and Everyday Life Norton: New York.

Stroumsa, GG, Religious memory, between orality and writing. Submitted for publication.

Suddendorf, T, \& Corballis, MC, (2007). The evolution of foresight: What is mental time travel and is it unique to humans. Behavioral and Brain Sciences, 30, 299-351. doi: 10.1017/S0140525X07001975

Susskind, L, \& Hrabovski, G, (2013). The Theoretical Minimum: What You Need to Know to Start Doing Physics. Basic Books:New York.

Toglia, J, \& Kirk, U, (2000). Understanding awareness deficits following brain injury. NeuroRehabilitation, 15, 57-70. 
Tulving, E, (1985). Memory and consciousness. Canadian Psychologist, 26, $1-12$.

Tulving, E, (2002). Episodic memory: From mind to brain. Annual Review of Psychology, 53, 1-25. http://dx.doi.org/10.1146/annurev.psych.53 .100901.1351145

Wang, Q, Remembering the self in cultural contexts: A cultural dynamic theory of autobiographical memory. Submitted for publication.

Weller, M, Memory, imagination, and the human spirit. Submitted for publication.

Young, JE, The memorial's arc: Between Berlin’s Denkmal and New York City’s 911 memorial. Submitted for publication.

Figure Legends

Figure1. An idealized RIS curve for past, present, and future events. 
Figure 2. Recalled recent and imagined near future events.

Figure 3. Thoughts at different times of the day. 
$\underline{\text { Authors Note }}$

The first two authors were partly supported by a Wellcome Trust Large Arts Award, Ref.: 102010/Z/13/Z. They thank the Trust for its support. 


\section{Biographical Sketches}

Martin A. Conway is Head of the Department of Psychology and a Director of the Center for Memory and Law at City University London, UK. He has researched human memory for over 30 years and is best known for his work into the nature of autobiographical memory.

Catherine Loveday is a Principal Lecturer in Cognitive Neuroscience at the University of Westminster. Much of her research is focused on the neuropsychology of autobiographical memory and she has worked for many years with people who have amnesia and dementia.

Scott Cole is a Postdoctoral Researcher affiliated with the Center on Autobiographical Memory (CON AMORE), Aarhus University, Denmark. His principal research interests concern the cognitive characteristics of future thinking. He has so far investigated the effect of ageing, neurological damage and retrieval processes in future thinking. 